\title{
Minutes Seconds Imputed
}

National Cancer Institute

\section{Source}

National Cancer Institute. Minutes Seconds Imputed. NCI Thesaurus. Code C81214.

An imputed time that includes the minute and second of observation. 